\title{
Human Astrocytes Are Resistant to Fas Ligand and Tumor Necrosis Factor-Related Apoptosis-Inducing Ligand-Induced Apoptosis
}

\author{
Jin H. Song, ${ }^{1}$ Anita Bellail, ${ }^{1}$ Margaret C. L. Tse, ${ }^{1}$ V. Wee Yong, ${ }^{2}$ and Chunhai Hao ${ }^{1}$ \\ ${ }^{1}$ Department of Pathology and Laboratory Medicine, Center of Neurodegenerative Disease and Winship Cancer Institute, Emory University School of \\ Medicine, Atlanta, Georgia 30322, and 2Department of Oncology and Clinical Neurosciences, University of Calgary, Calgary, Alberta, Canada T2N 4N1
}

\begin{abstract}
Human astrocytes express Fas yet are resistant to Fas-induced apoptosis. Here, we report that calcium/calmodulin-dependent protein kinase II (CaMKII) is constitutively activated in human astrocytes and protects the cells from apoptotic stimulation by Fas agonist. Once stimulated, Fas recruits Fas-associated death domain and caspase-8 for the assembly of the death-inducing signaling complex (DISC); however, caspase-8 cleavage is inhibited in the DISC. Inhibition of CaMKII kinase activity inhibits the expression of phosphoprotein enriched astrocytes-15 kDa/phosphoprotein enriched in diabetes (PEA-15/PED) and cellular Fas-associated death domain-like interleukin- $1 \beta$-converting enzyme-inhibitory protein (c-FLIP), thus releasing their inhibition of caspase- 8 cleavage. Inhibition of PEA15/PED or c-FLIP by small interfering RNA sensitizes human astrocytes to Fas-induced apoptosis. In contrast, inhibition of CaMKII, PEA-15, or c-FLIP does not affect the sensitivity of human astrocytes to tumor necrosis factor-related apoptosis-inducing ligand (TRAIL). TRAIL death receptors (DR4, DR5) are weakly expressed at mRNA, protein, and cell surface levels and thus fail to mediate the assembly of the DISC in human astrocytes. Overexpression of DR5 restores TRAIL signaling pathways and sensitizes the human astrocytes to TRAIL-induced apoptosis if CaMKII kinase activity or expression of PEA-15 and c-FLIP is inhibited; the results suggest that CaMKIImediated pathways prevent TRAIL-induced apoptosis in human astrocytes under conditions in which TRAIL death receptors are upregulated. This study has therefore identified the molecular mechanisms that protect normal human astrocytes from apoptosis induced by Fas ligand and TRAIL.
\end{abstract}

Key words: apoptosis; astrocytes; CaMKII; c-FLIP; Fas; TRAIL

\section{Introduction}

Tumor necrosis factor (TNF) family ligands are the main inducers of apoptosis in the CNS and thus contribute to brain injuries in many neurological diseases. TNF $\alpha$, the prototype of TNF family ligands, was reported in $\beta$-amyloid neurotoxicity in Alzheimer's disease (Meda et al., 1995). Fas ligand (FasL/CD95L) and tumor necrosis factor-related apoptosis-inducing ligand (TRAIL/Apo2L) were involved in neuronal death in cerebral ischemia (Martin-Villalba et al., 1999) and Alzheimer's disease (Ethell et al., 2002; Cantarella et al., 2003), as well as oligodendroglial death in multiple sclerosis (D'Souza et al., 1996; Matysiak et al., 2002). A recent report further implicated FasL in traumainduced apoptosis in neurons and oligodendrocytes (Demjen et al., 2004). In contrast to neurons and oligodendrocytes, astrocytes not only survive these insults but become reactive in re-

Received Aug. 22, 2005; revised Jan. 27, 2006; accepted Feb. 9, 2006.

This work was supported in part by the funds from the Department of Pathology and Laboratory Medicine, Emory University School of Medicine (C.H.), and a grant from the Canadian Institute of Health Research (V.W.Y.). C.H. is the Georgia Cancer Coalition Distinguished Scholar. We thank Dr. Alexander S. Easton for critical reading of this manuscript.

Correspondence should be addressed to Dr. Chunhai Hao, Department of Pathology and Laboratory Medicine, Emory University School of Medicine, 1365-C Clifton Road NE, Atlanta, GA 30322. E-mail: chao@emory.edu. DOI:10.1523/JNEUROSCI.5572-05.2006

Copyright $\odot 2006$ Society for Neuroscience $\quad$ 0270-6474/06/263299-10\$15.00/0 sponse (Dietrich et al., 2003). This promoted us to investigate the mechanisms that protect human astrocytes from FasL and TRAIL-induced apoptosis.

FasL and TRAIL triggers apoptosis through interaction with their death receptors (Fas, DR4/DR5) and subsequent recruitment of intracellular adaptor Fas-associated death domain (FADD) (Ashkenazi, 2002). FADD in turn recruits caspase-8 through interaction of their death effector domains (DED), leading to the assembly of death-inducing signaling complex (DISC) (Kischkel et al., 1995). In the DISC, caspase-8 is cleaved and activated through autoproteolysis (Muzio et al., 1998) and subsequently cleaves caspase-3 (Thornberry et al., 1997) and Bcl-2 inhibitory BH3-domain protein (Bid) (Li et al., 1998). The truncated Bid interacts with Bax and Bak and induces mitochondrial release of cytochrome $c$ into cytosol (Luo et al., 1998) in which caspase-9 is activated and cleaves caspase-3 (Li et al., 1997). Caspase- 3 in turn cleaves its substrates such as DNA fragmentation factor 45 (DFF45), leading to apoptosis (Liu et al., 1997).

The cleavage of caspase- 8 in the DISC is modulated by intracellular DED adaptor proteins. These include phosphoprotein enriched in astrocytes- $15 \mathrm{kDa}$ /phosphoprotein enriched in diabetes (PEA-15/PED) (Araujo et al., 1993; Condorelli et al., 1998) and cellular Fas-associated death domain-like interleukin- $1 \beta$ (IL-1 $\beta$ )-converting enzyme-inhibitory protein (c-FLIP) (Irmler 
et al., 1997). Both PEA-15/PED and c-FLIP are recruited to the DISC through the DED-DED interaction with FADD and caspase- 8 and thus inhibit caspase- 8 cleavage in the DISC. Phosphorylation of PEA-15/PED and c-FLIP influences their recruitment to the DISC and antiapoptotic functions (Xiao et al., 2002; Yang et al., 2003).

Calcium/calmodulin (CaM)-dependent protein kinase II (CaMKII) is widely distributed through the body but highly expressed in the CNS and involved in neuronal functions (Lisman et al., 2002). Here, we report that CaMKII mediates the expression and phosphorylation of PEA-15/PED and c-FLIP, which inhibit caspase-8 cleavage in human astrocytes. In contrast to Fas, DR4 and DR5 expression is insufficient to transduce TRAIL signals intracellularly in human astrocytes. Overexpression of DR5 restores TRAIL apoptotic signaling pathway and sensitizes human astrocytes to TRAIL-induced apoptosis if CaMKII kinase, PEA-15/PED, or c-FLIP is inhibited; the results suggest that CaMKII-mediated pathway inhibits TRAIL-induced apoptosis in human astrocytes as well.

\section{Materials and Methods}

Human astrocyte and neuron culture. Human neurons and astrocytes were generated from the brains of human embryos of 10-18 week fetal age after therapeutic abortion according to guidelines approved by local institutional ethics committees (Vecil et al., 2000; Corley et al., 2001). In brief, 5-15 g of brain tissue was diced into fragments of $\leq 1 \mathrm{~mm}$ and incubated in $40 \mathrm{ml}$ volume for $15 \mathrm{~min}$ at $37^{\circ} \mathrm{C}$ with $0.25 \%$ trypsin and 200 $\mu \mathrm{g} / \mathrm{ml}$ DNase I in PBS. The suspension was then washed through a filter of $130 \mu \mathrm{m}$ pore size, and the filtrate was centrifuged at $1200 \mathrm{rpm}$ for 10 min. For the generation of human astrocytes, the cell pellet was washed and suspended in the culture medium, and cells were plated into T-75 flasks coated with $10 \mu \mathrm{g} / \mathrm{ml}$ polyornithine. Plating density was 50 million cells in $25 \mathrm{ml}$ of MEM containing $0.1 \%$ dextrose, $100 \mu \mathrm{g} / \mathrm{ml}$ penicillinstreptomycin, $1 \mathrm{~mm}$ sodium pyruvate, $0.1 \mathrm{~mm}$ nonessential amino acids, $0.2 \mathrm{~mm}$ glutamine, and 10\% FCS (all medium constituents from Invitrogen, Carlsbad, CA). The cultures were passed three to five times and contained $>99 \%$ astrocytes as shown by immunostaining with antibody to glial fibrillary acidic protein. For the generation of human neurons, the cells were plated into culture flasks coated with $10 \mu \mathrm{g} / \mathrm{ml}$ polyornithine. The cells were cultured for $2 \mathrm{~d}$ in cytosine arabinoside-containing medium and an additional $3 \mathrm{~d}$ in the medium free of cytosine arabinoside before the cultures were subjected to Western blot.

Antibodies and reagents. Three recombinant human TRAIL proteins were used in this study: TRAIL (amino acids 114-291; PeproTech, Rocky Hill, NJ), Flag-tagged TRAIL (amino acids 95-281; Alexis Biochemicals, San Diego, CA); and histidine-tagged TRAIL (R \& D Systems, Minneapolis, MN). The following antibodies were used for flow cytometry: mouse monoclonal antibodies against DR4 and DR5 (Alexis Biochemicals), phycoerythrin (PE)-conjugated anti-human DR4 and DR5 (eBioscience, San Diego, CA), and PE-conjugated anti-human Fas and $\mathrm{IgG}_{1}$ isotype control (BD PharMingen, San Diego, CA). The following six antibodies against human DR4 and DR5 were used for Western blots: mouse monoclonal ab1-DR4 and ab1-DR5 (Alexis Biochemicals), rabbit antibody ab2-DR4 (Imgenex, San Diego, CA), ab2-DR4 (Chemicon, Temecula, CA), ab2-DR5 (ProSci, Poway, CA), and ab3-DR5 (Imgenex). Other monoclonal antibodies included anti-Fas (CH11; MBL, Woburn, MA), anti-Flag (M2; Sigma, Mississauga, Ontario, Canada), anti-human FADD (Transduction Laboratories, Lexington, KY), caspase-8 (Medical and Biological Laboratories, Nagoya, Japan), DFF45 (StressGen, Victoria, British Columbia, Canada), and c-FLIP NF6 (kind gift from Dr. Peter Krammer, German Cancer Research Center, Heidelberg, Germany) (Scaffidi et al., 1999). Rabbit antibodies were anti-human CaMKII $\alpha$ (M176) and phosphorylated CaMKII $\alpha$ (Thr286) (Santa Cruz Biotechnology, Santa Cruz, CA), caspase-3 (StressGen), and PEA-15/PED (kindly provided by Dr Francesco Beguinot, University of Naples, Naples, Italy) (Condorelli et al., 1998). HRP-conjugated goat anti-mouse $\kappa$ chain, $\operatorname{IgG}_{2 \mathrm{~b}}$, and $\operatorname{IgG}_{1}$ were from Southern Biotech (Birmingham, $A L$ ), and
HRP-conjugated goat anti-rabbit antibody was from Jackson ImmunoResearch (West Grove, PA). CaMKII inhibitor KN93 (2-[N-(2hydroxyethyl)]-N-(4-methoxybenzenesulfonyl)amino- $N$-(4-chlorocinnamyl)- $N$-methylbenzylamine), goat anti-mouse $\operatorname{IgG}_{1}$-agarose, goat anti-mouse IgM-agarose, complete protease inhibitor cocktail, Triton $\mathrm{X}-100$, and all other chemicals of analytical grade were from Sigma. CaMKII assay kit was purchased from Upstate Biotechnology (Lake Placid, NY), and $\left[\gamma_{-}{ }^{32} \mathrm{P}\right]$ ATP was from PerkinElmer (Boston, MA).

Flow cytometry. Cells $\left(10^{6}\right)$ were analyzed for the surface expression of DR4 and DR5 by indirect staining with mouse anti-human DR4 and DR5 (Alexis Biochemicals) followed by FITC-conjugated goat anti-mouse IgG antibody (Sigma) (Song et al., 2003a). Mouse IgG I $_{1}$ (DakoCytomation, High Wycombe, UK) was used for negative control. Phycoerythrinconjugated anti-human DR4, DR5, Fas, and IgG $_{1}$ isotype as control were also used based on the previous report (Song et al., 2003b). Cell surface expression of TRAIL receptors was analyzed and the data were processed using Flow software (Tree Star, Ashlang, OR).

Reverse transcription-PCR. Total RNA ( $3 \mu \mathrm{g})$ was extracted from cells using TRIzol reagent (Invitrogen) according to the recommendations of the manufacturer. The first-strand cDNA was synthesized by TaqMan transcription reagent (Applied Biosystems, Foster City, CA) with random hexamer. The sequences of specific primers used in this experiment were as follows: DR4 forward, 5' -CTGAGCAACGCAGACTCGCTGTCCAC-3'; DR4 reverse, 5'-AAGGACACGGCAGAG CCTGTGCCAT-3'; DR5 forward, 5'-CTGAAAGGCATCTGCTCAGGTG-3'; DR5 reverse, 5'-CAGAGTC TGCATTACCTTCTAG-3'; glyceraldehyde-3-phosphate dehydrogenase (GAPDH) forward, 5'-TGGTATCGTGGAAGGACTCATGAC-3'; GAPDH reverse, 5'-ATGCCAGTGAGCTTCCCGTTCAGT- $3^{\prime}$. The PCR reaction was performed with an initial denaturation at $94^{\circ} \mathrm{C}$ for $2 \mathrm{~min}$, followed by cycles of $30 \mathrm{~s}$ at $95^{\circ} \mathrm{C}, 30 \mathrm{~s}$ at $55^{\circ} \mathrm{C}$, and $45 \mathrm{~s}$ at $72^{\circ} \mathrm{C}$ using GoTaq Green Master Mix (Promega, Madison, WI). The PCR products were analyzed on a $1.5 \%$ agarose gel and stained with ethidium bromide.

Cell viability assay and cleavage of caspases and DFF45. For cell viability analysis, cells were seeded in 96-well plates at $2 \times 10^{4}$ cells per well and treated at $37^{\circ} \mathrm{C}$ with TRAIL or Fas agonistic $\mathrm{CH} 11$ antibody in the presence or absence of $100 \mu \mathrm{M}$ KN93 for the times indicated in Results. Cell viability was determined by crystal violet assay (Flick and Gifford, 1984). In brief, each well of 96-well plates was added with $100 \mu \mathrm{l}$ of a $2 \%$ paraformaldehyde solution and incubated at $4^{\circ} \mathrm{C}$ for $15 \mathrm{~min}$. The cells in each well were then stained with $100 \mathrm{ml}$ of crystal violet solution $(1 \%$ crystal violet, $1 \% \mathrm{HCl}$, and $10 \%$ ethanol) at $37^{\circ} \mathrm{C}$ for $10 \mathrm{~min}$. Absorbance was measured at $570 \mathrm{~nm}$ and used to calculate the percentage of viable cells against untreated control cells. For cleavage of caspases and DFF45, subconfluent cells were treated with either $1 \mu \mathrm{g} / \mathrm{ml} \mathrm{CH} 11$ or $1 \mu \mathrm{g} / \mathrm{ml}$ TRAIL at $37^{\circ} \mathrm{C}$ for the times indicated in Results. The cells were then lysed in lysis buffer (1\% Triton X-100, $150 \mathrm{~mm} \mathrm{NaCl}, 10 \%$ glycerol, 20 mм Tris- $\mathrm{HCl}$, pH 7.5, 2 mм EDTA, 1 mм phenylmethylsulfonyl fluoride, and complete protease inhibitor cocktail), and, after centrifugation at $18,000 \times g$ for $15 \mathrm{~min}$ at $4^{\circ} \mathrm{C}$, the supernatants were subjected to Western blotting.

The DISC analysis. FasL and TRAIL-induced DISC were analyzed based on the previously reported protocols (Xiao et al., 2002; Yang et al., 2003 , respectively). In brief, $1 \times 10^{7}$ cells were stimulated with either the mixture of $4 \mu \mathrm{g} / \mathrm{ml}$ Flag-tagged TRAIL and $6 \mu \mathrm{g} / \mathrm{ml}$ anti-Flag M2 (preincubated on ice for $15 \mathrm{~min}$ ) or $2 \mu \mathrm{g} / \mathrm{ml} \mathrm{CH} 11$ IgM antibody for $15 \mathrm{~min}$ at $37^{\circ} \mathrm{C}$ and then lysed for $30 \mathrm{~min}$ on ice with lysis buffer. The soluble fraction was immunoprecipitated either with $20 \mu$ l of goat anti-mouse $\mathrm{IgG}_{1}$-agarose (for TRAIL-DISC) or goat anti-mouse IgM-agarose (for Fas-DISC) overnight at $4^{\circ} \mathrm{C}$ and subjected to Western blotting. In unstimulated controls, the cells were lysed and treated with either the mixed Flag-TRAIL/anti-Flag M2 or CH11 antibody to immunoprecipitate nonstimulated death receptors.

Two-dimensional PAGE. For each sample, $10^{7}$ cells were treated or untreated with $25 \mu \mathrm{M} \mathrm{KN93}$ for $24 \mathrm{~h}$ at $37^{\circ} \mathrm{C}$ and then lysed in $40 \mathrm{~mm}$ Tris-HCl, pH 8.0, 1\% Triton X-100, 65 mm dithiothreitol, $0.5 \mathrm{~mm}$ phenylmethylsulfonyl fluoride, and complete protease inhibitor cocktail. After centrifugation, the supernatants were precipitated with acetone. The pellets were redissolved in $9.8 \mathrm{M}$ urea, 2\% 3-[(3-cholami- 
A
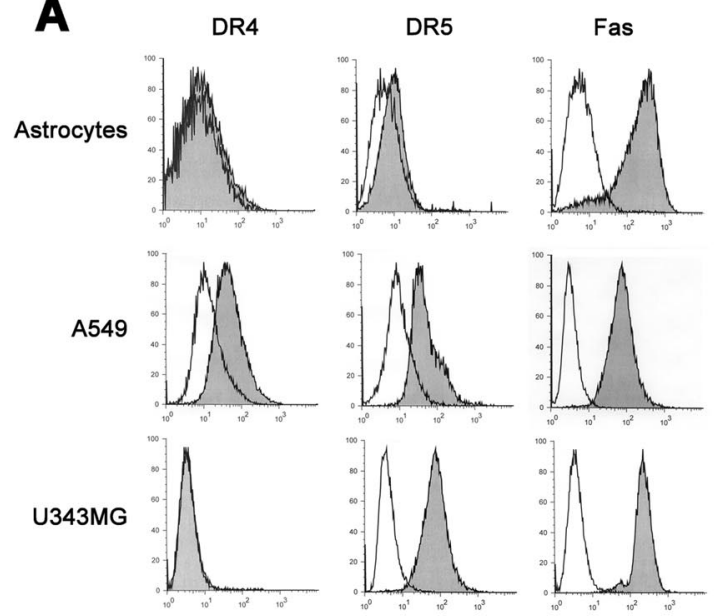

B

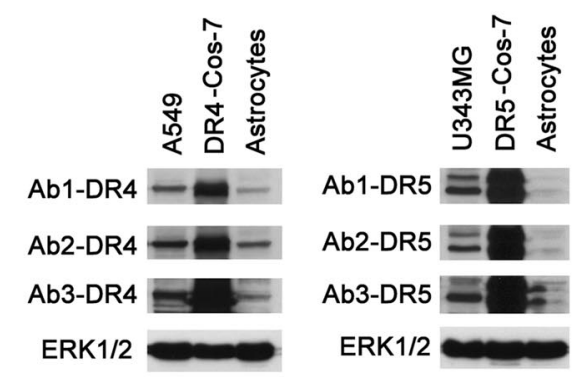

C
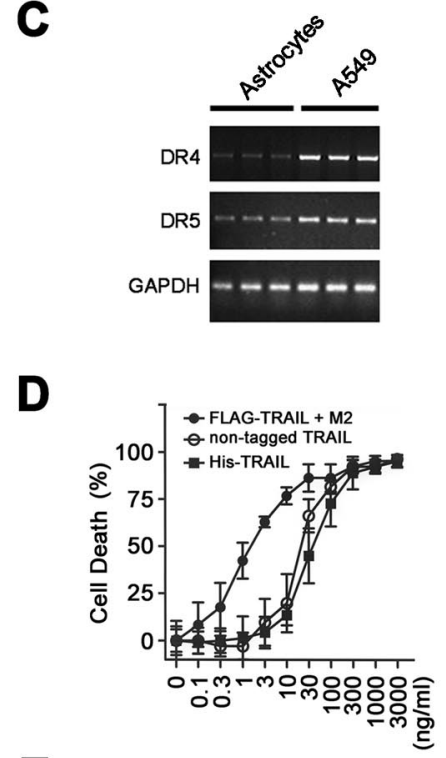

$\mathbf{E}$

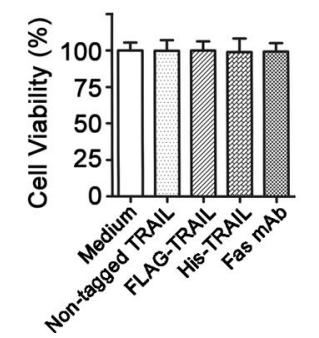

$\mathbf{F}$

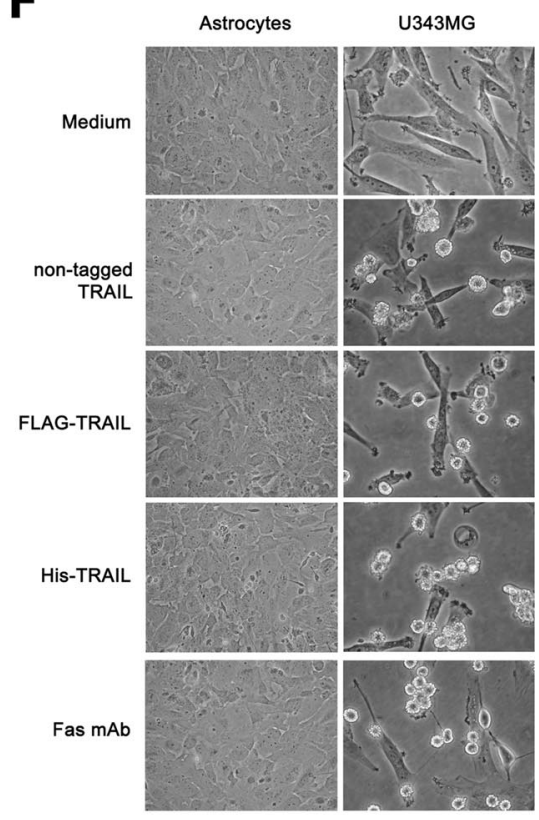

Figure 1. Human astrocytes are resistant to Fas agonist and TRAIL. A, Flow cytometry analysis of the cell surface expression of Fas, DR4, and DR5 in human astrocytes and A549 and U343MG cancer cell lines. $\boldsymbol{B}$, Western blot detection of DR4 and DR5 expression in human astrocytes, A549, U343MG, and Cos-7 cells transfected with either DR4 or DR5 CDNA. Three antibodies against DR4 and three antibodies to DR5 used in the study are indicated to the left and are described in Materials and Methods. Extracellular signal-regulated kinase 1/2 (ERK1/2) was used as protein loading control. C, RT-PCR analysis of DR4 and DR5 mRNA expression in human astrocytes and control A549 cells. D, Cell viability in human glioma cell line U343MG treated with the various doses of three recombinant forms of human TRAIL, as described in Materials and Methods. E, Cell viability analysis of human astrocytes after exposure to $3 \mu \mathrm{g} / \mathrm{ml}$ Fas agonist monoclonal antibody (Fas mAb), nontagged TRAIL (TRAIL), histidine-tagged TRAIL (his-TRAIL), and antibody cross-linked Flag-tagged TRAIL (Flag-TRAIL) for $24 \mathrm{~h}$. $\boldsymbol{F}$, Phase-contrast microscopic observation of apoptotic cell death in human glioma cell line U343MG but not human astrocytes after exposure to $3 \mu \mathrm{g} / \mathrm{ml}$ Fas agonist and various forms of recombinant TRAll. Cell viability data $(\boldsymbol{D}, \boldsymbol{E})$ were representative from three independent experiments (mean $\pm \mathrm{SEM} ; n=6$ ).

dopropyl)dimethylammonio]-1-propanesulfonate, $0.5 \%$ immobilized $\mathrm{pH}$ gradient (IPG) buffer ( $\mathrm{pH} 3-10$ nonlinear), and $65 \mathrm{~mm}$ dithiothreitol, applied by rehydration in $13 \mathrm{~cm}$ DryStrips ( $\mathrm{pH} 3-10$ ), and electrofocused with IPGphor System following the protocol of the manufacturer (Amersham Biosciences, Arlington Heights, IL). The strips were equilibrated with $50 \mathrm{~mm}$ Tris- $\mathrm{HCl}, \mathrm{pH} 8.8,6 \mathrm{~m}$ urea, 30\% glycerol, 2\% SDS, and 10 $\mathrm{mg} / \mathrm{ml}$ dithiothreitol and subjected to second-dimensional SDS-PAGE followed by nitrocellulose membrane transferring (Bio-Rad, Hercules, CA) and Western blotting with anti-PED serum (Xiao et al., 2002).

Western blots. Cell extracts and DISC samples were separated through SDS-PAGE on $15 \%$ gel and transferred to nitrocellulose membranes. The membranes were blocked with blocking buffer [ $5 \%$ nonfat dry milk in TBST (20 mм Tris-HCl, pH 7.5, $500 \mathrm{~mm} \mathrm{NaCl}$, and 0.5\% Tween 20)] for $1 \mathrm{~h}$ at room temperature and then incubated overnight at $4^{\circ} \mathrm{C}$ with primary antibody diluted in blocking buffer. The membranes were washed in TBST and incubated for $1 \mathrm{~h}$ at room temperature with the following secondary antibodies diluted in TBST: anti-mouse $\operatorname{IgG}_{2 \mathrm{~b}}-\mathrm{HRP}(1: 5000)$, and anti-mouse $\operatorname{IgG}_{1}-\mathrm{HRP}(1: 10,000)$, or anti-rabbit IgG-HRP (1:5000). The blots were washed and developed by chemiluminescence.

Synthesis and transfection of small interfering RNA. Double-stranded small interfering RNA (siRNA) duplexes specific to nucleotides 535-555 of the c-FLIP gene (GenBank accession number U97074) or 188-208 of the PEA-15/PED gene (GenBank accession number Y13736) were synthesized through Qiagen (Valencia, CA) service. The synthetic siRNA duplexes were transfected using TransMessenger transfection reagent (Qiagen) according to the protocol of the manufacturer. Transfected cells were allowed to grow for $36 \mathrm{~h}$ and then experimentally treated as outlined in Results.

DR5 and CaMKII cDNA constructs and transfection. DR5 cDNA was cloned into pcDNA3.1-Myc-HisA (kind gift from Dr. Wafik S. El-Deiry, University of Pennsylvania, Philadelphia, PA) (Wu et al., 1997). The pCD derivative SR $\alpha$ vector was the expression construct for $\alpha$-CaMKII K42M mutant (kinase death mutant attributable to changed ATP-binding pocket) (Hanson et al., 1994). Transient transfection of the expression vectors containing DR5 cDNA and $\alpha$-CaMKII K42M mutant was accomplished using the Lipofectamine method following the instructions of the manufacturer (Invitrogen). After $48 \mathrm{~h}$ of transfection, the cells were subjected to crystal violet cell viability assay or Western blotting.

CaMKII activity assay. CaMKII activity was assayed in cell lysates using CaMKII assay kits following the protocol of the manufacturer (Upstate Biotechnology, Mississauga, Ontario, Canada). Cells were pretreated or untreated with CaMKII inhibitor KN93 at $37^{\circ} \mathrm{C}$ for $24 \mathrm{~h}$ and then lysed with lysis buffer. Total proteins $(200 \mu \mathrm{g})$ were mixed with $10 \mu \mathrm{l}$ of a CaMKII substrate peptide (KKALRRQETVDAL). CaMK substrate, 0.4 $\mu \mathrm{M}$ each of peptide inhibitors for protein kinase A and protein kinase $\mathrm{C}$, and $100 \mu \mathrm{Ci}$ of $\mathrm{MgCl}_{2}-\left[\gamma_{-}{ }^{32} \mathrm{P}\right] \mathrm{ATP}$ in ADB II buffer (in mM: $203-(\mathrm{N}$ morpholino)-propanesulfonic acid, pH 7.2, $2.5 \beta$-glycerol phosphate, 1 sodium orthovanadate, 1 dithiothreitol, and $1 \mathrm{CaCl}_{2}$ ) were used. The reaction was incubated at $30^{\circ} \mathrm{C}$ for $10 \mathrm{~min}$. The phosphorylated substrate was separated from the residual $\left[\gamma^{32} \mathrm{P}\right]$ ATP using P81 phosphocellulose paper. The papers were washed, and radioactivity was measured by scintillation counting. CaMKII activity was measured as counts per minute 
per microgram of protein and calculated as picomoles as per the instructions of the manufacturer.

Statistical analyses. Statistical analysis was performed by one-way ANOVA followed by Bonferroni's $t$ test for multiple comparisons. Student's $t$ test was used when two groups were compared. Results are expressed as means \pm SEM values, and $p<0.05$ was regarded as significant.

\section{Results}

Human astrocytes are resistant to Fas agonist and TRAIL

Human astrocytes are well documented for the expression of FasL receptor Fas (Becher et al., 1998; Choi et al., 1999). In contrast, however, studies on TRAIL receptors have generated inconclusive results. Western blot analysis showed DR4 and DR5 expression in isolated fetal human astrocytes (Hao et al., 2001), whereas a double immunohistochemistry of adult human brain tissue located only DR4 in human astrocytes (Dorr et al., 2002). To clarify this issue, we generated a nearly pure culture of human fetal astrocytes and examined the expression of DR4 and DR5 at the cell surface, protein, and mRNA levels. Two human cancer cell lines were included as controls: human glioma U343MG expresses DR5 but not DR4 (Song et al., 2003b), whereas human lung cancer A549 expresses both DR4 and DR5. Flow cytometry detected Fas on the cell surface of human astrocytes and the cancer cell lines (Fig. $1 A$ ). In contrast, a minimal amount of DR4 was detected by one (Alexis Biochemicals) (Fig. $1 A$ ), but not by another (eBioscience) (data not shown) antibody. DR5 was detected by both antibodies but at much lower levels in human astrocytes compared with Fas (Fig. 1A). DR4 and DR5 protein expression was examined by Western blots using three antiDR4 and three anti-DR5 antibodies (see Materials and Methods). The specificity of each of the antibodies was examined by transfecting human DR4 and DR5 cDNA in Cos-7 cells (Fig. 1B). DR4 and DR5 proteins were detected in human astrocytes but at lower levels compared with Fas expression in human astrocytes and DR4 and DR5 expression in the human cancer cell lines (Fig. 1B). Finally, reverse transcription (RT)PCR detected DR4 and DR5 transcripts in human astrocytes, but their expression levels were lower than in the human cancer cell lines (Fig. 1C).

Several recombinant forms of human TRAIL have been reported, and their studies have generated controversies in TRAIL toxicity to human astrocytes. A recombinant TRAIL fused to a trimerizing leucine zipper motif was toxic to isolate adult human astrocytes (Walczak et al., 1999). Antibody cross-linked Flagtagged TRAIL was reported to damage human brain cells in brain
D

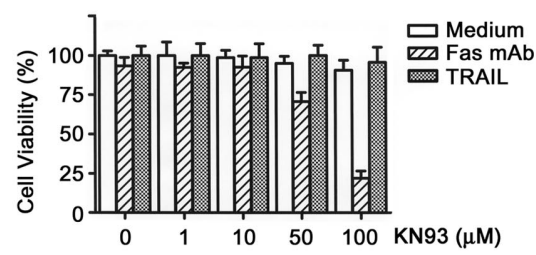

E

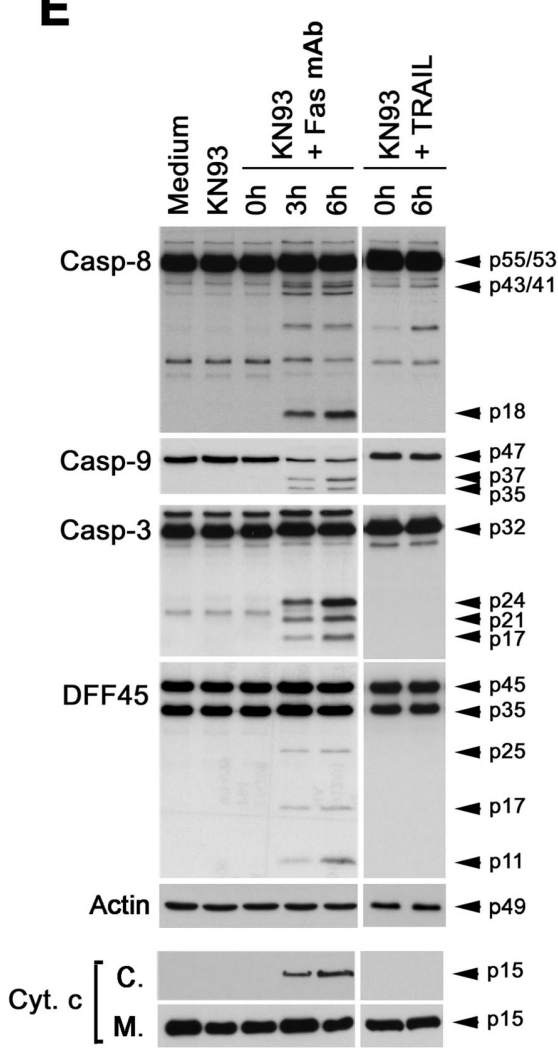

Figure 2. Inhibition of CaMKII sensitizes human astrocytes to Fas-induced apoptosis in human astrocytes. $\boldsymbol{A}$, Western blot analysis of the expression of CaMKII and phosphorylated CaMKII (p-CaMKII, Thr286) in human astrocytes $(\boldsymbol{A})$ and neurons $(\boldsymbol{N})$ untreated or treated with KN93 (100 $\mu \mathrm{M})$ for $24 \mathrm{~h}$. Actin was used as protein loading control. $\boldsymbol{B}$, CaMKIl kinase analysis for the kinase activity in human astrocytes treated with the various doses of KN93 for $24 \mathrm{~h}$ (mean $\pm \mathrm{SEM} ; n=3 ;{ }^{*} p<0.05$ ). $\boldsymbol{C}$, Phase-contrast microscopy examination of human astrocytes untreated or treated with TRAIL $(1 \mu \mathrm{g} / \mathrm{ml})$ and Fas agonist monoclonal antibody (Fas mAb; $1 \mu \mathrm{g} / \mathrm{ml}$ ) in the absence or presence of KN93 (100 $\mu \mathrm{m})$ for $24 \mathrm{~h}$. D. Cell viability analysis of human astrocytes after treatment for $24 \mathrm{~h}$ with various doses of KN93 in the absence or presence of Fas agonist ( $1 \mu \mathrm{g} / \mathrm{ml})$ and TRAIL (1 $\mu \mathrm{g} / \mathrm{ml}$ ) (mean $\pm \mathrm{SEM} ; n=6)$. $\boldsymbol{E}$, Western blot and subcellular fractionation analysis of cleavage of caspases and mitochondrial release of cytochrome $c$. Human astrocytes were treated with KN93 $(100 \mu \mathrm{m})$ for $16 \mathrm{~h}$ and then with Fas agonist $(1 \mu \mathrm{g} / \mathrm{ml})$ and TRAIL $(1 \mu \mathrm{g} / \mathrm{ml})$ for the times indicated at the top. Human astrocytes were also untreated (Medium) or treated alone with KN93 $(100 \mu \mathrm{M})$ for $22 \mathrm{~h}$ (KN93) as controls. The untreated and treated cells were subject to Western blot analysis of cleavage of caspases and DFF45 (panels 1-4) with actin as the protein loading control (panel 5). Subcellular fractionation of the cells showed the presence of cytochrome c in mitochondria (M.) and its release into cytosol (C.) after the treatment. The antibodies are indicated to the left, and the proteins detected are indicated to the right $(\boldsymbol{A}, \boldsymbol{E})$.

slice culture (Nitsch et al., 2000). In contrast, recombinant nontagged human TRAIL was reported to be nontoxic to isolated human fetal astrocytes (Hao et al., 2001). Simple explanation comes from the fact that these studies were conducted with different forms of recombinant TRAIL and different types of astrocytes in culture. To examine this further in human fetal astrocytes, we tested the toxicity of three recombinant forms of human TRAIL (nontagged TRAIL, histidine-tagged TRAIL, and antibody cross-linked Flag-tagged TRAIL) in human fetal astrocytes with the TRAIL-sensitive human glioma cell line U343MG in- 


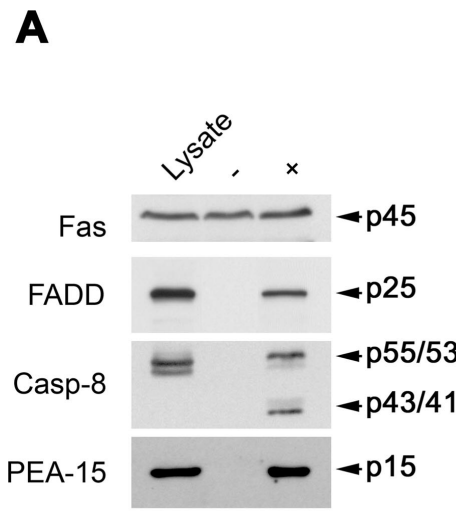

FAS-DISC
B

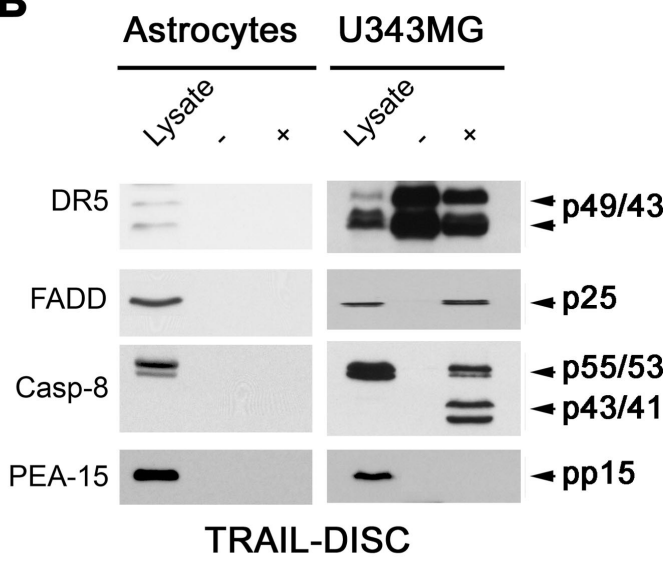

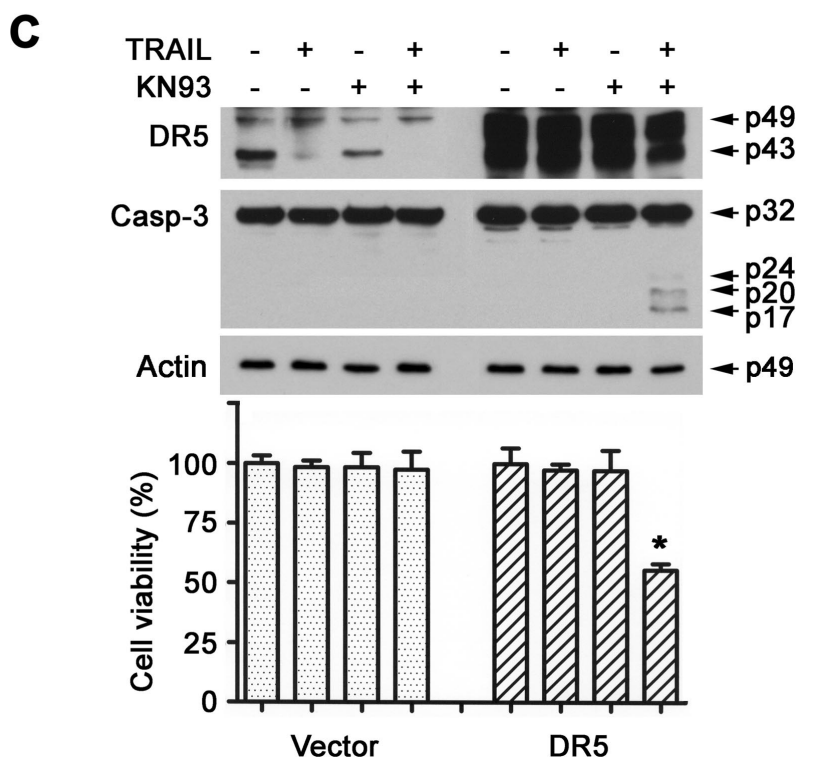

Figure 3. Insufficient expression of TRAIL receptors blocks TRAIL-induced signal pathway in human astrocytes. $A, B$, Analysis of Fas agonist $(\boldsymbol{A})$ and TRAIL-induced DISC $(\boldsymbol{B})$ in human astrocytes and human glioma U343MG cells. The DISC was immunoprecipitated by the treatment of human astrocytes with either Fas agonist antibody or Flag-tagged TRAlL for 15 min in stimulated cells $(+)$ or after cell lysis in unstimulated cells $(-)$. Cell lysates obtained from untreated cells (Lysate) were included as control for the expression of the endogenous proteins. C, TRAlL sensitivity of human astrocytes transfected with DR5 CDNA. Human astrocytes were transfected with DR5 CDNA for $48 \mathrm{~h}$ and treated with KN93 $(100 \mu \mathrm{M})$ and TRAIL $(1 \mu \mathrm{g} / \mathrm{ml})$, alone or in combination as indicated at the top. After $6 \mathrm{~h}$ of treatment, the cells were subjected to Western blot for DR5 expression (top) and caspase-3 cleavage (middle). After $24 \mathrm{~h}$ of treatment, the cells were analyzed for cell viability (bottom) (mean $\pm \mathrm{SEM} ; n=6 ;{ }^{*} p<0.05$ ).

cluded as positive control (Hao et al., 2001). Each of these recombinant forms of TRAIL was able to trigger cell death in U343MG cells in a dose-dependent manner (Fig. 1D); however, none of the reagents was toxic to human fetal astrocytes, as evident by cell viability analysis (Fig. $1 E$ ) and observation of apoptotic death of the cells under phase-contrast microscopy (Fig. $1 F$ ). Human astrocytes were also resistant to the treatment with FasL (data not shown) and Fas agonistic CH11 antibody (Fig. 1E,F).

\section{Inhibition of CaMKII restores Fas but not TRAIL apoptotic pathways}

CaMKII is highly expressed in the CNS and plays a role in neuronal survival and functions. To examine the role of CaMKII in protection of human astrocytes, we first examined its expression, activation, and kinase activity in the human astrocytes. Neuronal CaMKII has been well studied, and we therefore included human neurons in the analysis. Neuronal CaMKII is made up of 6-12 subunits, comprising $52 \mathrm{kDa} \alpha$ isoforms and $60 \mathrm{kDa} \beta$ isoforms (Miller and Kennedy, 1986). Neuronal CaMKII is activated by $\mathrm{Ca}^{2+} /$ calmodulin $(\mathrm{CaM})$ and the binding of $\mathrm{Ca}^{2+} / \mathrm{CaM}$ allows CaMKII to be phosphorylated at Thr286 in the $\alpha$ isoform and Thr287 in the $\beta$ isoform (Miller and Kennedy, 1986). This starts an autophosphorylation process that makes CaMKII independent of $\mathrm{Ca}^{2+} / \mathrm{CaM}$ and thus makes it constitutively active. Western blots detected CaMKII protein in both the human astrocytes and neurons (Fig. $2 A$ ). The Thr286 phosphorylated CaMKII $\alpha$ isoform was further demonstrated in the human astrocytes and neurons by Western blots with the antibody specific to Thr286phosphorylated CaMKII $\alpha$ (Fig. 2A). CaMKII kinase assay using a CaMKIIspecific peptide substrate identified CaMKII kinase activity in the human astrocytes (Fig. $2 B$ ). The results indicate that CaMKII is constitutively phosphorylated and activated in the human astrocytes.

We then examined whether inhibition of CaMKII kinase activity changes the cell sensitivity to Fas agonist antibody and TRAIL. The human astrocytes were treated for $24 \mathrm{~h}$ with various doses $(1-100$ $\mu \mathrm{M})$ of KN93, a chemical inhibitor of CaMKII kinase, and the results showed that KN93 inhibited CaMKII kinase activity significantly at $100 \mu \mathrm{M}$ (Fig. $2 \mathrm{~B}$ ). The human astrocytes were then treated for $24 \mathrm{~h}$ with various doses $(1-100 \mu \mathrm{M})$ of KN93 in the presence of $1 \mu \mathrm{g} / \mathrm{ml}$ Fas agonist $\mathrm{CH} 11$ antibody or nontagged human TRAIL. In the presence of KN93 (50 and $100 \mu \mathrm{M}$ ), the human astrocytes became sensitive to Fas agonist but not to TRAIL, as observed by phase-contrast microscopy (Fig. 2C) and cell viability assay (Fig. 2D). The experiment was repeated using histidine-tagged TRAIL or Flag-tagged TRAIL M2 mixed with M2 anti-Flag, and results showed that none of these TRAIL reagents was toxic to human astrocytes (data not shown).

To determine whether the cell death is apoptotic, the treated human astrocytes were examined for cleavage of caspases and mitochondrial release of cytochrome $c$. Caspase-8 exists in two isoforms ( $\mathrm{p} 55, \mathrm{p} 53$ ), and both isoforms are cleaved through two consecutive steps (Medema et al., 1997). Indeed, Western blots detected caspase-8 first-step cleavage (p43, p41) and second-step cleavage (p18) products in the human astrocytes after combination treatment with $\mathrm{KN} 93(100 \mu \mathrm{M})$ and Fas agonist $(1 \mu \mathrm{g} / \mathrm{ml})$ for 3 and $6 \mathrm{~h}$ (Fig. 2E). The cleavage products of caspase-9, caspase- 3 , and DFF45 were also detected in the treated cells (Fig. 2E). The treated astrocytes were subjected to subcellular fractionation and Western blot analysis of the cytosolic fractions free of mitochondria revealed the release of mitochondrial cytochrome $c$ (Fig. 2E). In contrast, however, Western blot and subcellular fractionation detected neither cleavage of the caspases nor mitochondrial release of cytochrome $c$ in the human astrocytes treated with KN93 
$(100 \mu \mathrm{M})$ and TRAIL $(1 \mu \mathrm{g} / \mathrm{ml})$ (Fig. $2 E)$. The results suggest that CaMKII kinase activity protects human astrocytes from the apoptotic stimulation by Fas agonist but not TRAIL.

\section{Death receptors fail to couple TRAIL to intracellular signaling pathways}

Failure to detect casapase- 8 cleavage in the KN93- and TRAIL-treated human astrocytes (Fig. 2E) suggests that TRAIL resistance may occur in the DISC, the most upstream component of the TRAIL signaling. The poor expression of DR4 and DR5 in human astrocytes (Fig. $1 B, C$ ) further support the notion that DR4 and DR5 expression may be insufficient for TRAIL binding and induction of the TRAIL-DISC assembly. In contrast, Fas is highly expressed and thus capable of inducing FasDISC assembly in human astrocytes. To test these hypotheses, we first examined the Fas-DISC in human astrocytes. The human astrocytes were stimulated with Fas agonist $\mathrm{CH} 11$ antibody $(1 \mu \mathrm{g} / \mathrm{ml})$ for $15 \mathrm{~min}$, and Fas-induced DISC was immunoprecipitated. Western blots detected Fas, FADD, caspase-8, and PEA-15/PED in the Fas-DISC (Fig. 3A). The detection of caspase- 8 proenzymes ( $\mathrm{p} 55 / \mathrm{p} 53$ ) and firststep cleavage product $(\mathrm{p} 43 / 42)$ in the DISC (Fig. 3A) suggests that caspase- 8 proenzymes complete their first-step cleavage in the DISC. Detection of PEA15/PED in the DISC suggests that PEA-15/ PED may inhibit the second-step cleavage of caspase- 8 in the DISC (Fig. $3 A$ ).

We then examined TRAIL-induced DISC. The human astrocytes were stimulated with the mixed Flag-TRAIL and M2 anti-Flag antibody and the DISC was immunoprecipitated. Western blots failed to detect DR5, FADD, caspase-8, and PEA15/PED in the TRAIL-induced DISC (Fig. 3B). These results suggest that the expression of DR4 and DR5 is insufficient for TRAIL binding and coupling to intracellular signaling pathways. To test this hypothesis, we conducted two additional experiments. We first examined the binding capability of Flag-TRAIL on TRAIL receptors. The human malignant glioma U343MG cell line was TRAIL sensitive because of the low expression of CaMKII and PEA-15/PED cells (Xiao et al., 2002). U343MG cells were treated with Flag-TRAIL/M2 antibody, and Western blots indeed detected DR5, FADD, and caspase- 8 but not PEA-15/PED in the TRAIL-induced DISC. We then overexpressed DR5 in the astrocytes and examined whether DR5 overexpression would restore the cell sensitivity to TRAIL. The astrocytes were transfected with DR5 cDNA for $48 \mathrm{~h}$, and the overexpression of DR5 protein was confirmed by Western blots (Fig. 3C). The DR5 cDNAtransfected astrocytes were then treated with KN93 $(100 \mu \mathrm{M})$ and TRAIL $(1 \mu \mathrm{g} / \mathrm{ml})$ for 6 or $24 \mathrm{~h}$ and subjected to Western blot and cell viability assay, respectively (Fig. $3 C$ ). The treatment of the transfected astrocytes with KN93 or TRAIL alone did not cause cell death; however, the combination treatment with KN93 and
B
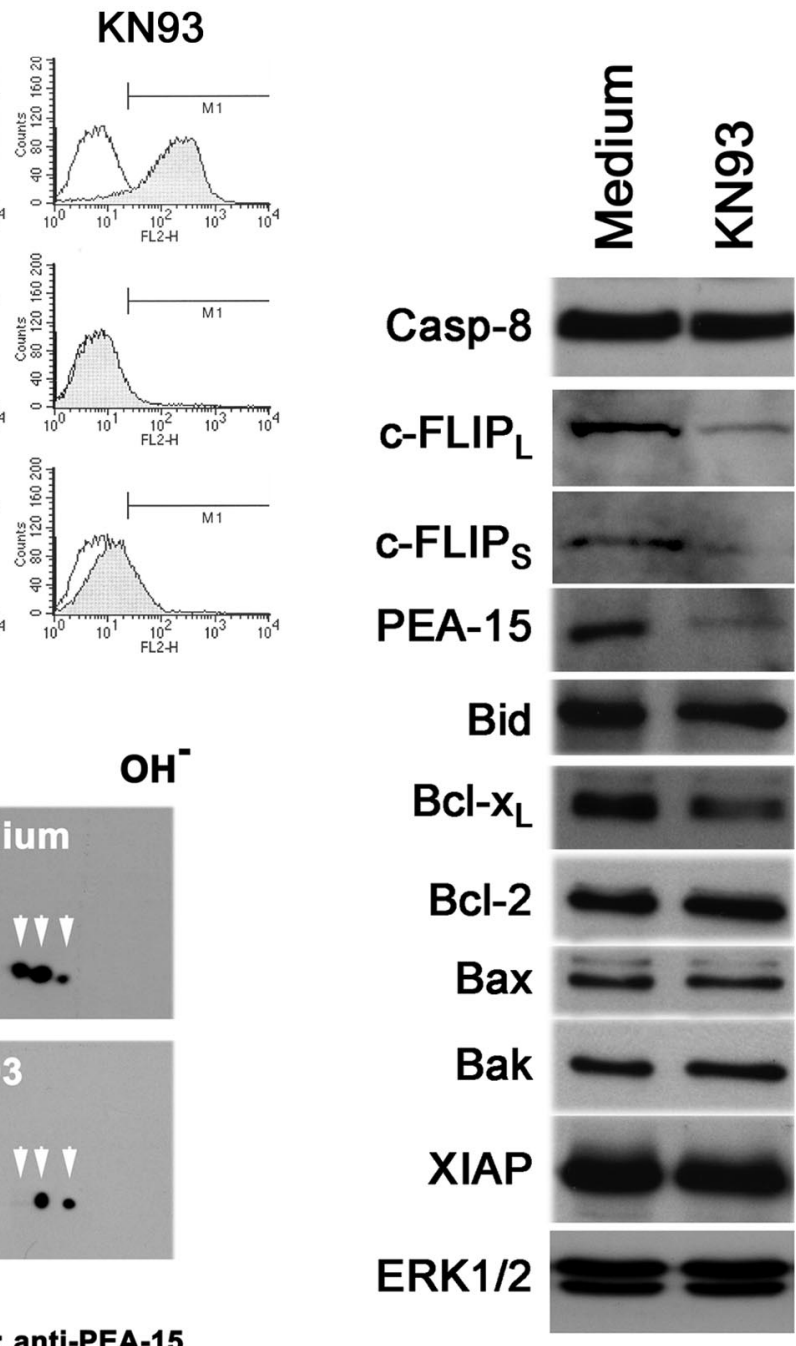

PEA-15

Figure 4. CaMKII inhibitor KN93 inhibits PEA-15/PED and c-FLIP expression. Human astrocytes were treated or untreated (Medium) with KN93 $(100 \mu \mathrm{M})$ for $24 \mathrm{~h}$ and then subjected to flow cytometry analysis of Fas and DR5 expression $(\boldsymbol{A})$, Western blot analysis of the expression of key apoptotic proteins $(\boldsymbol{B})$, and two-dimensional PAGE analysis of PEA-15/PED isoforms (C). The antibodies are indicated to the left $(\boldsymbol{B})$. The isoelectric direction $\left(\mathrm{H}^{+}, \mathrm{OH}^{-}\right)$of two-dimensional PAGE is indicated above $(\boldsymbol{C})$.

TRAIL triggered apoptotic cell death, as shown by cleavage of caspase- 3 and cell death in the human astrocytes transfected with DR5 cDNA (Fig. 3C). The results suggest that CaMKII kinase activity protects human astrocytes from TRAIL-induced apoptosis under conditions in which TRAIL receptors are upregulated.

\section{CaMKII regulates the expression of c-FLIP and PEA-15/PED}

The finding that inhibition of CaMKII restores the sensitivity of human astrocytes to the death ligands suggests that CaMKII may modulate the proteins involved in the death ligand signaling. We therefore treated human astrocytes with KN93 (100 $\mu \mathrm{M})$ for $24 \mathrm{~h}$ and examined the expression of the proteins known in the death receptor signaling pathways. Flow cytometry (Fig. 4A) showed no significant difference in the expression of Fas and DR5 among the KN93-treated and untreated human astrocytes. Western blot analysis also showed no significant difference in the expression of caspase-8, Bcl-2 family proteins (Bid, Bcl-2, Bax, Bak), and $\mathrm{X}$-linked inhibitor of apoptosis protein (XIAP) in the treated and untreated astrocytes, except for Bcl- $\mathrm{X}_{\mathrm{L}}$, which was slightly downregulated (Fig. $4 B$ ). 
In contrast, KN93 treatment significantly inhibited the expression of PEA-15/PED and c-FLIP proteins (Fig. $4 B$ ). c-FLIP protein exists in two forms: the short form $\left(\mathrm{c}-\mathrm{FLIP}_{\mathrm{S}}, M_{\mathrm{r}}\right.$ of $\sim 28$ $\mathrm{kDa}$ ) and the long form (c-FLIP $\mathrm{L}_{\mathrm{r}}, M_{\mathrm{r}}$ of $\sim 55 \mathrm{kDa}$ ) (Irmler et al.,

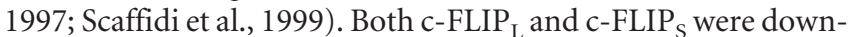
regulated in the KN93-treated astrocytes (Fig. 4B). PEA-15/PED is phosphorylated on two residues: Ser 104 by protein kinase $C$ and Ser116 by CaMKII (Araujo et al., 1993; Estelles et al., 1996) and thus exists in three forms: unphosphorylated, single phosphorylated, and double phosphorylated (Xiao et al., 2002). Twodimensional PAGE immunoblots detected the three forms of PEA-15/PED protein in the untreated human astrocytes (Fig. $4 C$ ); however, the treatment with KN93 eliminated the doublephosphorylated PEA-15/PED protein (Fig. 4C). These results suggest that CaMKII regulates both the expression and phosphorylation of PEA-15/PED protein in human astrocytes.

\section{CaMKII-mediated c-FLIP and PED pathway protects human astrocytes}

To further define the roles of CaMKII, PEA-15/PED, and c-FLIP in death receptor-mediated apoptosis, we specifically inhibited the expression of each of these proteins in human astrocytes. First, CaMKII expression in the human astrocytes was inhibited by transfection of CaMKII dominant negative, $\alpha$-CaMKII K42M mutant, and empty vector as controls (Hanson et al., 1994). Transfection of $\alpha$-CaMKII K42M mutant for $48 \mathrm{~h}$ inhibited the expression of PEA-15/PED, c-FLIP ${ }_{\mathrm{L}}$, and $\mathrm{c}-\mathrm{FLIP}_{\mathrm{S}}$ in the human astrocytes, as evident by Western blots (Fig. $5 A$ ). The transfectants were then treated with either Fas agonist $\mathrm{CH} 11$ antibody (1 $\mu \mathrm{g} / \mathrm{ml})$ or recombinant nontagged TRAIL $(1 \mu \mathrm{g} / \mathrm{ml})$ for $6 \mathrm{~h}$ in Western blot analysis (Fig. $5 B$ ) or for $24 \mathrm{~h}$ in cell viability assay (Fig. 5C). The transfection of $\alpha$-CaMKII K42M mutant sensitized the human astrocytes to Fas-mediated apoptosis but not to TRAIL-induced apoptosis (Fig. 5).

We then inhibited the expression of PEA-15/PED and c-FLIP in human astrocytes with synthetic siRNA specifically targeting the PEA-15/PED and $c$-FLIP genes. To inhibit both c-FLIP ${ }_{\mathrm{L}}$ and ${ }_{C-F L I P}$, we designed c-FLIP siRNA specific to the nucleotides $535-555$ in the c-FLIP DED sequence shared by both c-FLIP ${ }_{L}$ and

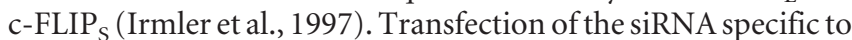
PEA-15/PED and c-FLIP in human astrocytes for $24 \mathrm{~h}$ significantly inhibited the expression of PEA-15/PED and c-FLIP protein, respectively (Fig. 6A). The transfected human astrocytes were then treated with Fas agonist $\mathrm{CH} 11$ antibody $(1 \mu \mathrm{g} / \mathrm{ml})$ for $6 \mathrm{~h}$, and Western blots detected the cleavage products of caspase- 8 and caspase- 3 in the astrocytes transfected with the siRNA to PEA-15/PED and c-FLIP but not nonspecific control siRNA (Fig. 6B). The human astrocytes transfected with PEA-15/ PED and c-FLIP siRNA were also treated with Fas agonist CH11 antibody $(1 \mu \mathrm{g} / \mathrm{ml})$ for $24 \mathrm{~h}$, and cell viability assay revealed a significant cell death (Fig. 6C).

We finally examined the sensitivity of human astrocytes to TRAIL under the condition of DR5 overexpression. The human astrocytes were first transfected with DR5 cDNA for $48 \mathrm{~h}$ to overexpress DR5 (Fig. 6D). The DR5 cDNA-transfected astrocytes were then transfected with either PEA-15/PED siRNA or c-FLIP siRNA for $24 \mathrm{~h}$ to inhibit expression of each of the proteins (Fig. $6 A)$. The double-transfected astrocytes were treated with nontagged TRAIL $(1 \mu \mathrm{g} / \mathrm{ml})$ for $6 \mathrm{~h}$ for Western blot (Fig. $6 D)$ and $24 \mathrm{~h}$ for cell viability assay (Fig. $6 \mathrm{D}$ ). The results showed that the transfection with DR5 cDNA together with either PEA-15/PED siRNA or c-FLIP siRNA resulted in the sensitivity of human astrocytes to TRAIL-induced apoptosis. Collectively, these studies
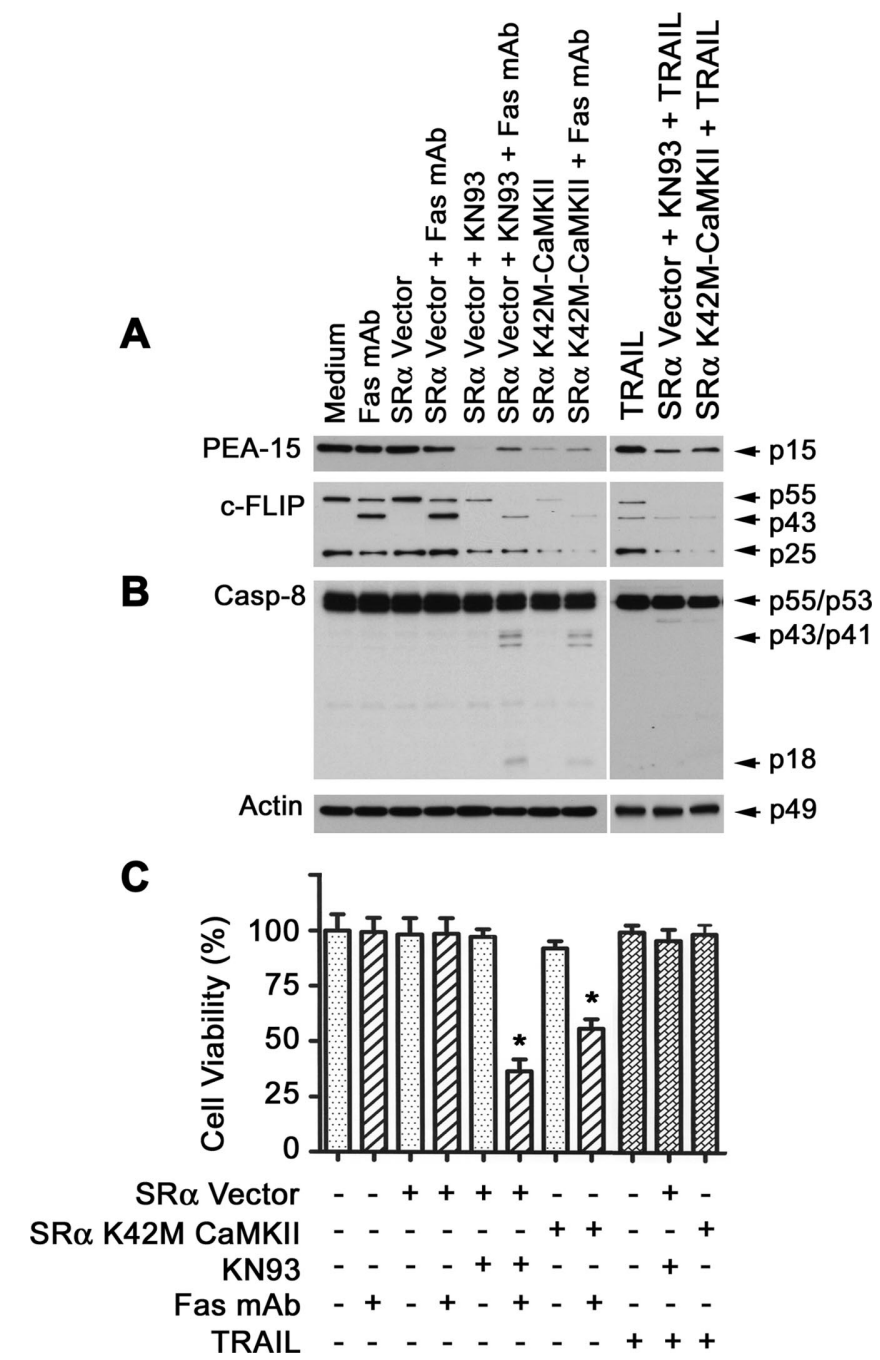

Figure 5. CaMKII dominant negative sensitizes human astrocytes to Fas but not TRAIL. Human astrocytes were transfected with pCD derivative SR $\alpha$ vector expressing $\alpha$-CaMKII K42M mutant or empty SR $\alpha$ vector for $48 \mathrm{~h}$. Some of the astrocytes transfected with empty SR $\alpha$ vector were untreated or treated with KN93 $(100 \mu \mathrm{m})$ and Fas agonist $(1 \mu \mathrm{g} / \mathrm{ml})$, alone or in combination, for $6 \mathrm{~h}$ for Western blot analysis $(\boldsymbol{A}, \boldsymbol{B})$ and $24 \mathrm{~h}$ for cell viability analysis $(\boldsymbol{C})$. Some of the astrocytes transfected with the $\alpha$-CaMKII K42M mutant were untreated or treated with Fas agonist $(1 \mu \mathrm{g} / \mathrm{ml})$ or nontagged TRAIL $(1 \mu \mathrm{g} / \mathrm{ml})$ for $6 \mathrm{~h}$ for Western blot analysis $(\boldsymbol{A}, \boldsymbol{B})$ and $24 \mathrm{~h}$ for cell viability analysis ( $C$ (mean $\pm \mathrm{SEM} ; n=6)$. Human astrocytes untreated (Medium) or treated with Fas agonist $(1 \mu \mathrm{g} / \mathrm{ml})$ were included in the examination as controls. The treatments are indicated at the top, the antibodies used are indicated to the left, and the proteins detected are indicated to the right $(\boldsymbol{A}, \boldsymbol{B}) .{ }^{*} p<0.05$.

indicate that CaMKII-mediated c-FLIP and PEA-15/PED pathways protect human astrocytes from Fas agonist and TRAILinduced apoptosis.

\section{Discussion}

Astrocytes are the most numerous cell type in the CNS and provide structural, trophic, and metabolic environments for normal neuronal functions and regeneration after brain injuries (Pekny and Nilsson, 2005). These functionalities depend on the ability of astrocytes first to survive brain insults and then to quickly become active in response to the insults. Here, we report two molecular mechanisms by which human astrocytes survive the apoptotic insults by FasL and TRAIL. First, CaMKII kinase is constitutively phosphorylated and activated in human astrocytes and mediates the expression and phosphorylation of c-FLIP and 
PEA-15/PED, which in turn inhibit caspase- 8 cleavage in the DISC and thus prevent Fas-mediated apoptosis in human astrocytes. Second, TRAIL receptor DR4 and DR5 are insufficiently expressed in human astrocytes, and, as a result, the receptors fail to interact with TRAIL and couple to intracellular proteins necessary for assembly of the DISC.

The expression and apoptotic function of FasL and Fas have been well documented in the CNS (Choi and Benveniste, 2004). However, the molecular mechanisms that modulate FasL/Fas pathways in human brain cells remain essentially unknown. Fas is constitutively expressed in human astrocytes in culture (Becher et al., 1998; Choi et al., 1999), as well as reactive astrocytes in neurological diseases (Dowling et al., 1996; Ferrer et al., 2001). In response to Fas stimulation, human astrocytes produce IL- 8 and express the IL-8 receptor CXCR2 (Saas et al., 1999, 2002; Lee et al., 2000). Human astrocytes therefore express functional Fas but are resistant to FasL killing. Several studies have suggested the molecular mechanisms in Fas resistance. Interferon- $\gamma($ IFN- $\gamma)$ upregulates Fas expression in human astrocytes and sensitizes the cells to FasL killing; this study suggests that Fas expression levels may define cell resistance to Fas killing (Choi et al., 1999; Saas et al., 1999). However, other groups have reported that Fas stimulation does not kill human astrocytes regardless of IFN- $\gamma$ treatment (Lee et al., 2000; Wosik et al., 2001). The lack of caspase- 8 expression has been reported as a possible reason for human astrocyte survival; however, this seems limited to one of the human fetal astrocyte cultures (Wosik et al., 2001). In this study, we show that caspase- 8 is expressed and capable of initiating the caspase cascade in execution of programmed cell death in human fetal astrocytes. In addition, this study suggests that c-FLIP and PEA-15/PED-mediated inhibition of caspase- 8 cleavage provides one of the molecular pathways responsible for Fas resistance in human fetal astrocytes.

In contrast to FasL, very little is known about the TRAIL pathways in human astrocytes. The literature currently available is rather controversial. A recombinant human TRAIL (amino acids 95-281) $\mathrm{N}$ terminally fused to a trimerizing leucine zipper motif is toxic to isolated human adult astrocytes (Walczak et al., 1999), whereas antibody cross-linked Flag-tagged human TRAIL (amino acids 95-281) causes damage to brain cells in human brain slice cultures (Nitsch et al., 2000; Dorr et al., 2005). In contrast, nontagged recombinant forms of human TRAIL (amino acids 114-281) are nontoxic to human fetal astrocytes (Hao et al., 2001). These controversies appear because of the usage of different recombinant forms of human TRAIL and culture conditions of human astrocytes. Unfortunately, none of these studies has provided underlying molecular mechanisms with each of the recombinant forms of TRAIL and the particular types of cells. In this study, we conducted a series of studies of TRAIL signaling in human fetal astrocytes. Human fetal astrocytes are resistant to all three forms of human TRAIL examined: nontagged, histidine-tagged, and antibody cross-linked Flagtagged TRAIL. The insufficient expression of TRAIL receptor
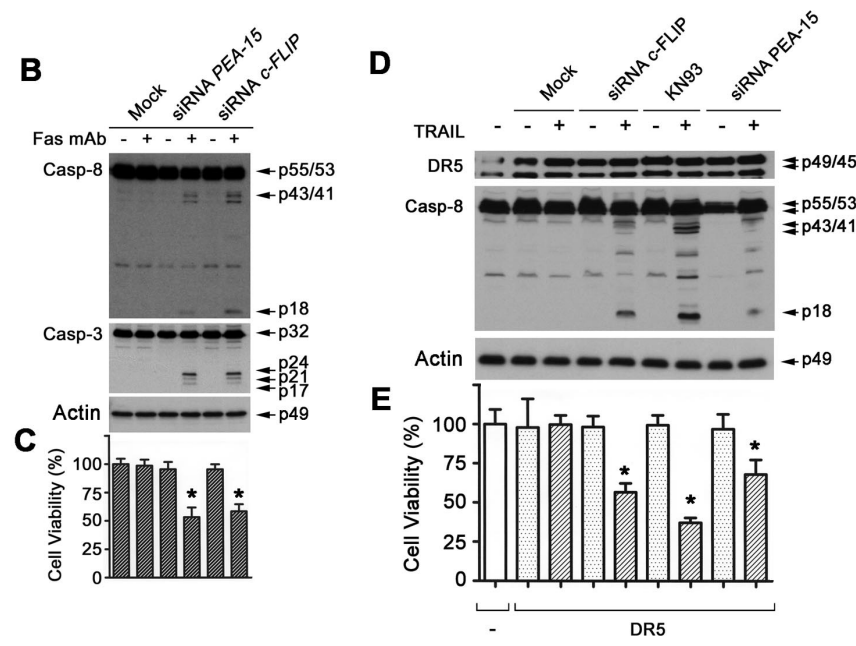

DR5

Figure 6. Effects of siRNA specific to PEA-15/PED and c-FLIP on Fas and TRAIL of human astrocytes. $\boldsymbol{A}$, Western blot analysis of with nontagged TRAIL ( $1 \mu \mathrm{g} / \mathrm{ml}$ ) for $6 \mathrm{~h}$ for Western blot detection of caspase-8 cleavage $(\boldsymbol{D})$ or for $24 \mathrm{~h}$ for cell viability analysis $(\boldsymbol{E})$ in which each value represents six samples, and * indicates the significance $(p<0.05)(\boldsymbol{C})$.

DR4 and DR5 on the cell surface of human fetal astrocytes contributes to the cell resistance to TRAIL.

However, overexpression of TRAIL receptor DR5 does not sensitize human fetal astrocytes to TRAIL-induced apoptosis, unless the expression of PEA-15 or c-FLIP is inhibited in the cells. It therefore seems that human fetal astrocytes have a double level of protection against TRAIL apoptotic activation. First, the expression of TRAIL receptors on the cell surface is insufficient enough to link the TRAIL to intracellular signal pathways. Second, PEA-15/PED and c-FLIP inhibit caspase- 8 cleavage and thus prevent TRAIL-induced apoptosis even when TRAIL receptors are experimentally upregulated in human astrocytes. This provides a window opportunity to use TRAIL in treatment of human malignant gliomas of astrocytic lineage. Human malignant glioma cells overexpress TRAIL receptors and therefore undergo apoptosis under TRAIL treatment (Hao et al., 2001). Human malignant gliomas, however, are genetically heterogeneous, and, as a result, some of the malignant glioma cells overexpress CaMKII-mediated PEA-15/PED and c-FLIP pathways and thus are resistant to TRAIL (Xiao et al., 2002). Chemotherapy downregulates PEA-15 and c-FLIP and results in TRAIL sensitivity in the resistant glioma cells (Song et al., 2003b). The insufficient expression of TRAIL receptors in normal human cells, such as astrocytes as demonstrated here and hepatocytes as we reported previously (Hao et al., 2004), blocks TRAIL signaling and thus prevents normal human cells from TRAIL-induced apoptosis even in the combination treatment with TRAIL and chemotherapy.

PEA-15/PED and c-FLIP inhibit FasL and TRAIL-induced apoptosis through interruption of DED-DED interaction of FADD and caspase- 8 in the DISC (Xiao et al., 2002; Yang et al., 2003). PEA-15/PED is mainly expressed in astrocytes, and it has been reported to inhibit TNF $\alpha$-induced apoptosis in murine astrocytes (Renault et al., 2003). In this study, we provided several lines of evidence that PEA-15/PED inhibits FasL-induced apoptosis in human astrocytes. In contrast, however, very little is known about c-FLIP in human astrocytes, except one study reporting 
expression and cleavage of c-FLIP $_{\mathrm{L}}$ in human fetal astrocytes (Wosik et al., 2001). The data presented here have shown that both c-FLIP ${ }_{\mathrm{L}}$ and c-FLIP $\mathrm{S}_{\mathrm{S}}$ are expressed and inhibit Fas-induced apoptosis in human fetal astrocytes. CaMKII mediates c-FLIP expression in human fetal astrocytes and thus protects the cells from Fas and TRAIL-induced apoptosis.

The study presented here provides a molecular model in death receptor-mediated signaling in human astrocytes; however, the question remains whether this model demonstrated in human fetal astrocytes can be generalized for adult astrocytes in normal brains and reactive astrocytes in diseased brains. Indeed, contradictive results have been generated in the studies of human adult astrocytes. Leucine zipper-tagged TRAIL was reported to kill human astrocytes isolated from adult brains (Walczak et al., 1999); antibody cross-linked Flag-tagged TRAIL caused apoptotic cell death in human adult brain slices (Nitsch et al., 2000; Dorr et al., 2005). Immunohistochemistry locates DR4 but not DR5 in the astrocytes of human adult epileptic brains (Dorr et al., 2002). Clearly additional molecular studies of each of the culture models derived from normal or diseased brains are required to delineate death receptor-mediated signaling pathways and thus define the their roles in normal and diseased brains.

CaMKII is a multifunctional serine/threonine kinase that phosphorylates substrates in cytoplasm and mediates gene expression through its nuclear location (Schulman, 2004). CaMKII has been well studied in neurons but not astrocytes, particularly of human origin. Neuronal CaMKII is activated by $\mathrm{Ca}^{2+} / \mathrm{CaM}$, and the binding of $\mathrm{Ca}^{2+} / \mathrm{CaM}$ allows CaMKII to be phosphorylated. The phosphorylation makes CaMKII independent of $\mathrm{Ca}^{2+} / \mathrm{CaM}$, and it become constitutively active. In this study, we examined human fetal astrocytes, together with human fetal neurons. The results presented here have shown that CaMKII is constitutively expressed, phosphorylated, and activated in human fetal neurons and astrocytes. Moreover, we have shown that CaMKII kinase activity is required for human fetal astrocyte survival of the proapoptotic action of the death ligands. The studies have further identified the CaMKII-mediated PEA-15/PED and c-FLIP pathways as one of the molecular mechanisms that protect normal human fetal astrocytes from FasL and TRAILinduced apoptosis. This study therefore provides useful information in our understanding of the molecular pathways by which astrocytes survive apoptosis induced by the death ligands and may use their non-apoptotic actions to become active, so contributing to the repair of tissue injuries in the CNS.

\section{References}

Araujo H, Danziger N, Cordier J, Glowinski J, Chneiweiss H (1993) Characterization of PEA-15, a major substrate for protein kinase C in astrocytes. J Biol Chem 268:5911-5920.

Ashkenazi A (2002) Targeting death and decoy receptors of the tumournecrosis factor superfamily. Nat Rev Cancer 2:420-430.

Becher B, D’Souza SD, Troutt AB, Antel JP (1998) Fas expression on human fetal astrocytes without susceptibility to fas-mediated cytotoxicity. Neuroscience 84:627-634.

Cantarella G, Uberti D, Carsana T, Lombardo G, Bernardini R, Memo M (2003) Neutralization of TRAIL death pathway protects human neuronal cell line from beta-amyloid toxicity. Cell Death Differ 10:134-141.

Choi C, Benveniste EN (2004) Fas ligand/Fas system in the brain: regulator of immune and apoptotic responses. Brain Res Brain Res Rev 44:65-81.

Choi C, Park JY, Lee J, Lim JH, Shin EC, Ahn YS, Kim CH, Kim SJ, Kim JD, Choi IS, Choi IH (1999) Fas ligand and Fas are expressed constitutively in human astrocytes and the expression increases with IL-1, IL-6, TNFalpha, or IFN-gamma. J Immunol 162:1889-1895.

Condorelli G, Vigliotta G, Iavarone C, Caruso M, Tocchetti CG, Andreozzi F, Cafieri A, Tecce MF, Formisano P, Beguinot L, Beguinot F (1998) PED/
PEA-15 gene controls glucose transport and is overexpressed in type 2 diabetes mellitus. EMBO J 17:3858-3866.

Corley SM, Ladiwala U, Besson A, Yong VW (2001) Astrocytes attenuate oligodendrocyte death in vitro through an alpha(6) integrin-laminindependent mechanism. Glia 36:281-294.

Demjen D, Klussmann S, Kleber S, Zuliani C, Stieltjes B, Metzger C, Hirt UA, Walczak H, Falk W, Essig M, Edler L, Krammer PH, Martin-Villalba A (2004) Neutralization of CD95 ligand promotes regeneration and functional recovery after spinal cord injury. Nat Med 10:389-395.

Dietrich PY, Walker PR, Saas P (2003) Death receptors on reactive astrocytes: a key role in the fine tuning of brain inflammation? Neurology 60:548-554.

Dorr J, Bechmann I, Waiczies S, Aktas O, Walczak H, Krammer PH, Nitsch R, Zipp F (2002) Lack of tumor necrosis factor-related apoptosis-inducing ligand but presence of its receptors in the human brain. J Neurosci 22:RC209(1-5).

Dorr J, Roth K, Zurbuchen U, Deisz R, Bechmann I, Lehmann TN, Meier S, Nitsch R, Zipp F (2005) Tumor-necrosis-factor-related apoptosisinducing-ligand (TRAIL)-mediated death of neurons in living human brain tissue is inhibited by flupirtine-maleate. J Neuroimmunol 167:204-209.

Dowling P, Shang G, Raval S, Menonna J, Cook S, Husar W (1996) Involvement of the CD95 (APO-1/Fas) receptor/ligand system in multiple sclerosis brain. J Exp Med 184:1513-1518.

D'Souza SD, Bonetti B, Balasingam V, Cashman NR, Barker PA, Troutt AB, Raine CS, Antel JP (1996) Multiple sclerosis: Fas signaling in oligodendrocyte cell death. J Exp Med 184:2361-2370.

Estelles A, Yokoyama M, Nothias F, Vincent JD, Glowinski J, Vernier P, Chneiweiss H (1996) The major astrocytic phosphoprotein PEA-15 is encoded by two mRNAs conserved on their full length in mouse and human. J Biol Chem 271:14800-14806.

Ethell DW, Kinloch R, Green DR (2002) Metalloproteinase shedding of Fas ligand regulates beta-amyloid neurotoxicity. Curr Biol 12:1595-1600.

Ferrer I, Puig B, Krupinsk J, Carmona M, Blanco R (2001) Fas and Fas ligand expression in Alzheimer's disease. Acta Neuropathol (Berl) 102:121-131.

Flick DA, Gifford GE (1984) Comparison of in vitro cell cytotoxic assays for tumor necrosis factor. J Immunol Methods 68:167-175.

Hanson PI, Meyer T, Stryer L, Schulman H (1994) Dual role of calmodulin in autophosphorylation of multifunctional CaM kinase may underlie decoding of calcium signals. Neuron 12:943-956.

Hao C, Beguinot F, Condorelli G, Trencia A, Van Meir EG, Yong VW, Parney IF, Roa WH, Petruk KC (2001) Induction and intracellular regulation of tumor necrosis factor-related apoptosis-inducing ligand (TRAIL) mediated apoptosis in human malignant glioma cells. Cancer Res 61:1162-1170.

Hao C, Song JH, Hsi B, Lewis J, Song DK, Petruk KC, Tyrrell DL, Kneteman NM (2004) TRAIL inhibits tumor growth but is nontoxic to human hepatocytes in chimeric mice. Cancer Res 64:8502-8506.

Irmler M, Thome M, Hahne M, Schneider P, Hofmann K, Steiner V, Bodmer JL, Schroter M, Burns K, Mattmann C, Rimoldi D, French LE, Tschopp J (1997) Inhibition of death receptor signals by cellular FLIP. Nature 388:190-195.

Kischkel FC, Hellbardt S, Behrmann I, Germer M, Pawlita M, Krammer PH, Peter ME (1995) Cytotoxicity-dependent APO-1 (Fas/CD95)associated proteins form a death-inducing signaling complex (DISC) with the receptor. EMBO J 14:5579-5588.

Lee SJ, Zhou T, Choi C, Wang Z, Benveniste EN (2000) Differential regulation and function of Fas expression on glial cells. J Immunol 164:1277-1285.

Li H, Zhu H, Xu CJ, Yuan J (1998) Cleavage of BID by caspase 8 mediates the mitochondrial damage in the Fas pathway of apoptosis. Cell 94:491-501.

Li P, Nijhawan D, Budihardjo I, Srinivasula SM, Ahmad M, Alnemri ES, Wang X (1997) Cytochrome c and dATP-dependent formation of Apaf-1/caspase-9 complex initiates an apoptotic protease cascade. Cell 91:479-489.

Lisman J, Schulman H, Cline H (2002) The molecular basis of CaMKII function in synaptic and behavioural memory. Nat Rev Neurosci 3:175-190.

Liu X, Zou H, Slaughter C, Wang X (1997) DFF, a heterodimeric protein that functions downstream of caspase-3 to trigger DNA fragmentation during apoptosis. Cell 89:175-184.

Luo X, Budihardjo I, Zou H, Slaughter C, Wang X (1998) Bid, a Bcl2 interacting protein, mediates cytochrome $\mathrm{c}$ release from mitochondria in response to activation of cell surface death receptors. Cell 94:481-490.

Martin-Villalba A, Herr I, Jeremias I, Hahne M, Brandt R, Vogel J, Schenkel J, Herdegen T, Debatin KM (1999) CD95 ligand (Fas-L/APO-1L) and tu- 
mor necrosis factor-related apoptosis-inducing ligand mediate ischemiainduced apoptosis in neurons. J Neurosci 19:3809-3817.

Matysiak M, Jurewicz A, Jaskolski D, Selmaj K (2002) TRAIL induces death of human oligodendrocytes isolated from adult brain. Brain 125:2469-2480.

Meda L, Cassatella MA, Szendrei GI, Otvos L Jr, Baron P, Villalba M, Ferrari D, Rossi F (1995) Activation of microglial cells by beta-amyloid protein and interferon-gamma. Nature 374:647-650.

Medema JP, Scaffidi C, Kischkel FC, Shevchenko A, Mann M, Krammer PH, Peter ME (1997) FLICE is activated by association with the CD95 deathinducing signaling complex (DISC). EMBO J 16:2794-2804.

Miller SG, Kennedy MB (1986) Regulation of brain type II $\mathrm{Ca}^{2+} /$ calmodulin-dependent protein kinase by autophosphorylation: $\mathrm{a} \mathrm{Ca}^{2+}$ triggered molecular switch. Cell 44:861-870.

Muzio M, Stockwell BR, Stennicke HR, Salvesen GS, Dixit VM (1998) An induced proximity model for caspase-8 activation. J Biol Chem 273:2926-2930

Nitsch R, Bechmann I, Deisz RA, Haas D, Lehmann TN, Wendling U, Zipp F (2000) Human brain-cell death induced by tumour-necrosis-factorrelated apoptosis-inducing ligand (TRAIL). Lancet 356:827-828.

Pekny M, Nilsson M (2005) Astrocyte activation and reactive gliosis. Glia 50:427-434.

Renault F, Formstecher E, Callebaut I, Junier MP, Chneiweiss H (2003) The multifunctional protein PEA-15 is involved in the control of apoptosis and cell cycle in astrocytes. Biochem Pharmacol 66:1581-1588.

Saas P, Boucraut J, Quiquerez AL, Schnuriger V, Perrin G, Desplat-Jego S, Bernard D, Walker PR, Dietrich PY (1999) CD95 (Fas/Apo-1) as a receptor governing astrocyte apoptotic or inflammatory responses: a key role in brain inflammation? J Immunol 162:2326-2333.

Saas P, Walker PR, Quiquerez AL, Chalmers DE, Arrighi JF, Lienard A, Boucraut J, Dietrich PY (2002) A self-defence mechanism of astrocytes against Fas-mediated death involving interleukin-8 and CXCR2. NeuroReport 13:1921-1924.

Scaffidi C, Schmitz I, Krammer PH, Peter ME (1999) The role of c-FLIP in modulation of CD95-induced apoptosis. J Biol Chem 274:1541-1548.

Schulman H (2004) Activity-dependent regulation of calcium/calmodulindependent protein kinase II localization. J Neurosci 24:8399-8403.
Song JH, Song DK, Herlyn M, Petruk KC, Hao C (2003a) Cisplatin downregulation of cellular Fas-associated death domain-like interleukin1beta-converting enzyme-like inhibitory proteins to restore tumor necrosis factor-related apoptosis-inducing ligand-induced apoptosis in human melanoma cells. Clin Cancer Res 9:4255-4266.

Song JH, Song DK, Pyrzynska B, Petruk KC, Van Meir EG, Hao C (2003b) TRAIL triggers apoptosis in malignant glioma cells through extrinsic and intrinsic pathways. Brain Pathol 13:539-553.

Thornberry NA, Rano TA, Peterson EP, Rasper DM, Timkey T, Garcia-Calvo M, Houtzager VM, Nordstrom PA, Roy S, Vaillancourt JP, Chapman KT, Nicholson DW (1997) A combinatorial approach defines specificities of members of the caspase family and granzyme B. Functional relationships established for key mediators of apoptosis. J Biol Chem 272:17907-17911.

Vecil GG, Larsen PH, Corley SM, Herx LM, Besson A, Goodyer CG, Yong VW (2000) Interleukin-1 is a key regulator of matrix metalloproteinase-9 expression in human neurons in culture and following mouse brain trauma in vivo. J Neurosci Res 61:212-224.

Walczak H, Miller RE, Ariail K, Gliniak B, Griffith TS, Kubin M, Chin W, Jones J, Woodward A, Le T, Smith C, Smolak P, Goodwin RG, Rauch CT, Schuh JC, Lynch DH (1999) Tumoricidal activity of tumor necrosis factor-related apoptosis-inducing ligand in vivo. Nat Med 5:157-163.

Wosik K, Becher B, Ezman A, Nalbantoglu J, Antel JP (2001) Caspase 8 expression and signaling in Fas injury-resistant human fetal astrocytes. Glia 33:217-224.

Wu GS, Burns TF, McDonald III ER, Jiang W, Meng R, Krantz ID, Kao G, Gan DD, Zhou JY, Muschel R, Hamilton SR, Spinner NB, Markowitz S, Wu G, el-Deiry WS (1997) KILLER/DR5 is a DNA damage-inducible p53regulated death receptor gene. Nat Genet 17:141-143.

Xiao C, Yang BF, Asadi N, Beguinot F, Hao C (2002) Tumor necrosis factorrelated apoptosis-inducing ligand-induced death-inducing signaling complex and its modulation by c-FLIP and PED/PEA-15 in glioma cells. J Biol Chem 277:25020-25025.

Yang BF, Xiao C, Roa WH, Krammer PH, Hao C (2003) Calcium/ calmodulin-dependent protein kinase II regulation of c-FLIP expression and phosphorylation in modulation of Fas-mediated signaling in malignant glioma cells. J Biol Chem 278:7043-7050. 